\title{
Evaluation of the effect of calcium gluconate and bovine thrombin on the temporal release of transforming growth factor beta 1 and platelet-derived growth factor isoform BB from feline platelet concentrates
}

\author{
Raul F Silva ${ }^{1,2^{*}}$, María E Álvarez ${ }^{1}$, Diana L Ríos ${ }^{1}$, Catalina López ${ }^{1}$, Jorge U Carmona ${ }^{1}$ and Cleuza MF Rezende ${ }^{2}$
}

\begin{abstract}
Background: There are not reported regarding the protocols for obtaining platelet concentrates (PC) in cats for medical purposes. The objectives of this study were: 1) to describe a manual method for producing two kinds of PC in cats (PC-A and PC-B), 2) to describe the cellular population of the PC, 3) to measure and compare the effect of calcium gluconate (CG) and bovine thrombin (BT) on the temporal release of transforming growth factor beta 1 (TGF- $\beta_{1}$ ) and platelet-derived growth factor type BB (PDGF-BB) at 3 and 12 hours post-activation and 4) to establish correlations between the cellular population of both PCs and the concentration of growth factors (GF). Blood samples were taken from 16 cats for complete blood count, plasma collection and PC preparation. The PC were arbitrarily divided into two fractions, specifically, PC-A (lower fraction) and PC-B (upper fraction).
\end{abstract}

Results: The platelet counts were significantly different $(P<0.05)$ between the $P C$ and whole blood but not between the PC fractions. The TGF- $\beta_{1}$ concentration efficiencies for PC-A and PC-B activated with CG were $42.86 \%$ and $46.54 \%$, and activated with BT were $42.88 \%$ and $54.64 \%$, respectively. The PDGF-BB concentration efficiencies for PC-A and PC-B activated with CG were $61.36 \%$ and $60.61 \%$, and activated with BT were $65.64 \%$ and $72.12 \%$, respectively. The temporal release of GFs showed no statistically significant difference $(P>0.05)$ between the activating substances at the time or for any PC fraction.

Conclusions: Whatever the activation means, these preparations of cat PC provide significant concentrations of platelets and GFs for possible clinical or experimental use.

Keywords: Calcium gluconate, Cat, Bovine thrombin, Platelet rich plasma, Regenerative medicine

\section{Background}

The clinical use of autologous platelet concentrates (PC) for regenerative aims in veterinary medicine has focused on the field of equine medicine and surgery [1]. To date, there are studies indicating the clinical utility of several types of PC in horses with musculoskeletal disease [2-4] and limb skin wounds [5]. PC has also been evaluated as a coadjutant substance (alone or in combination with

\footnotetext{
*Correspondence: raul.silva@ucaldas.edu.co

${ }^{1}$ Grupo de Investigación Terapia Regenerativa, Departamento de Salud Animal, Universidad de Caldas, Caldas, Colombia

${ }^{2}$ Departamento de Clinica e Cirurgia Veterinárias, Universidade Federal de Minas Gerais, Minas Gerais, Brazil
}

\section{Ciomed Central}

(c) 2012 Silva et al.; licensee BioMed Central Ltd. This is an Open Access article distributed under the terms of the Creative Commons Attribution License (http://creativecommons.org/licenses/by/2.0), which permits unrestricted use, distribution, and reproduction in any medium, provided the original work is properly cited.

\section{$[6,7]$ and osseous integration [8].}

The rationale for the use of $\mathrm{PC}$ stems from the fact that platelets (after being activated) release substantial amounts of growth factors (GF) and other molecules that modulate inflammation and tissue repair [9]. Platelets store at least 7 GFs directly implicated in wound healing and tissue homeostasis. However, transforming growth factor beta 1 (TGF- $\left.\beta_{1}\right)$ and platelet-derived growth factor type BB (PDGF-BB) are mainly contained in platelet alpha granules. These proteins are essential, 
among other biological actions, for extracellular matrix (ECM) deposition, angiogenesis and cell migration [10].

Recently, a equine PC classification has been proposed for improving the knowledge on the kind of cells and growth factors (GF) that are being used in horses with natural disease. Briefly, liquid PC (those in what a anticoagulant is used for their elaboration) could be classified in pure-platelet rich plasma (P-PRP) and leukocyteplatelet rich plasma (L-PRP). P-PRP is characterized by a platelet count slightly higher $(1.3-4 \mathrm{x})$ to the basal count of platelets in whole blood and the leukocyte count is lower than or similar to the leukocyte count in whole blood. On the other hand, L-PRP has increased platelet ( 5 fold) and leukocyte ( 3 fold or more) counts when compared to whole blood [1].

Either, P-PRP or L-PRP have been used clinically alone or after activation with several substances, such as calcium salts and thrombin (either from a bovine or autogenous source), among others. Calcium is an important second messenger in the platelet activation cascade because calcium mediates the characteristic platelet activation responses, such as shape change, granule secretion and aggregation [11]. The activation of platelets by most stimulatory agents leads to an increase in the concentration of cytosolic calcium (Ca2+). Platelet responses that are directly dependent on an increase in $(\mathrm{Ca} 2+)$ include integrin activation, release of the second wave mediators, ADP and thromboxane A2 (TxA2), and the expression of platelet procoagulant activity mainly by the generation of thrombin [12].

Thrombin is the most potent platelet activator. Thrombin produces fibrin generation from fibrinogen and also contributes to the formation and consolidation of the hemostatic plug [13]. This protein generates signaling cascades within the platelets by interacting with two membrane receptors coupled to $\mathrm{G}$ proteins belonging to the family of protease-activated receptors (PAR) and known as PAR1 and PAR4 [14].

Cats can develop various chronic musculoskeletal problems and suffer serious traumatic injuries [15] that may be susceptible to treatment with platelet concentrates, as happens with humans [16-19] and horses [2,20,21]. PC could also be used as a coadjutant biomaterial in orthopedic surgery in cats [22]. However, after reviewing the literature, we have not found any reports regarding the protocols for obtaining PC in cats for regenerative medicine purposes. We also did not find any published data about the concentration and temporal release of GF (such as TGF- $\beta_{1}$ and PDGF-BB) from feline PC activated with calcium salts or thrombin.

The aims of this study were 1) to describe a manual method for producing two kinds of PC in cats, PC-A and $\mathrm{PC}-\mathrm{B}, 2)$ to describe the cellular population of the $\mathrm{PC}$ obtained, 3) to measure and compare the effects of calcium gluconate (CG) and bovine thrombin (BT) on the temporal release of TGF- $\beta_{1}$ and PDGF-BB from feline PC at 3 and $12 \mathrm{~h}$ post-activation and 4) to establish possible correlations between the cellular population present in the $\mathrm{PC}$ and the concentration of growth factors.

\section{Results}

Hemogram

The packed cell volume, counts for PLT, absolute counts for MON and GRA and MPV and PDW were significantly different $(\mathrm{P}<0.05)$ among the two $\mathrm{PC}$ and the whole blood. However, the platelet parameters did not differ significantly between each PC. The WBC counts were significantly different $(\mathrm{P}<0.05)$ among the whole blood, PC-A and PC-B. The situation was the same for the relative counts for LYM, MON, GRA and EOS. However, the absolute count for LYM was similar between the whole blood and PC-A but differed statistically $(\mathrm{P}<0.05)$ for $\mathrm{PC}-\mathrm{B}($ Table 1$)$.

\section{Total protein concentration}

The total protein concentration was significantly lower $(\mathrm{P}<0.05)$ in both $\mathrm{PC}$ in comparison with plasma. However, this parameter did not differ between each PC (Table 2).

\section{Transforming growth factor beta 1 concentration}

The concentrations for TGF- $\beta_{1}$ were similar between each $\mathrm{PC}$ but significantly higher $(\mathrm{P}<0.05)$ in comparison with the plasma. Both activating substances presented a similar effect on the release of this growth factor over

Table 1 Cell counts / $\mu \mathrm{L}$ in whole blood, portions A - B of autologous platelet concentrates (PC)

\begin{tabular}{llll}
\hline Variable & Whole Blood & PC-A & PC-B \\
\hline Platelets $\times 10^{3} / \mu \mathrm{L}$ & $349.35(28.64)$ & $639.62(44.30) \mathrm{a}$ & $605.34(41.72) \mathrm{a}$ \\
$\mathrm{PCV} \%$ & $33.73(0.99)$ & $2.23(0.30) \mathrm{a}$ & $1.32(0.17) \mathrm{a}$ \\
$\mathrm{RBC} \times 10^{3} / \mu \mathrm{L}$ & $7151(282)$ & $425(26,8) \mathrm{a}$ & $323(35,9) \mathrm{b}$ \\
WBC $\times 10^{3} / \mu \mathrm{L}$ & $7.91(0.75)$ & $5.19(0.65) \mathrm{a}$ & $2.24(0.35) \mathrm{b}$ \\
Lymphocytes $\times 10^{3} / \mu \mathrm{L}$ & $3.22(0.26)$ & $3.44(0.34) \mathrm{a}$ & $1.84(0.31) \mathrm{b}$ \\
Lymphocytes \% & $42.80(3.50)$ & $71.19(4.31) \mathrm{a}$ & $79.25(2.93) \mathrm{a}$ \\
Monocytes $\times 10^{3} / \mu \mathrm{L}$ & $1.09(0.02)$ & $0.35(0.01) \mathrm{a}$ & $0.00(0.00) \mathrm{a}$ \\
Monocytes \% & $1.28(0.23)$ & $0.39(0.17) \mathrm{a}$ & $0.00(0.00) \mathrm{b}$ \\
Granulocytes $\times 10^{3} / \mu \mathrm{L}$ & $4.18(0.53)$ & $1.52(0.30) \mathrm{a}$ & $0.40(0.07) \mathrm{a}$ \\
Granulocytes \% & $51.54(3.28)$ & $26.14(3.83) \mathrm{a}$ & $20.13(2.97) \mathrm{b}$ \\
Eosinophils $\times 10^{3} / \mu \mathrm{L}$ & $0.40(0.08)$ & $0.20(0.07) \mathrm{a}$ & $0.00(0.00) \mathrm{a}$ \\
Eosinophils \% & $4.46(0.57)$ & $2.35(0.89) \mathrm{a}$ & $0.00(0.00) \mathrm{b}$ \\
MPV (fL) & $8.96(0.38)$ & $11.58(0.46) \mathrm{a}$ & $11.57(0.44) \mathrm{a}$ \\
PDW \% & $15.51(0.38)$ & $16.66(0.34) \mathrm{a}$ & $16.88(0.28) \mathrm{a}$ \\
\hline
\end{tabular}

Data presented as means (standard error). PCV, hematocrit; RBC, red blood cell; WBC, leukocytes; MPV, Mean Platelet Volume; PDW, Platelet Distribution Width. ${ }^{\mathbf{a}-\mathbf{b}}$ Different letters denote statistically significant differences between rows (PC-A vs. PC-B) by SNK test $(\mathrm{P}<0.05)$. 
Table 2 Concentration of growth factors in plasma, supernatants of PC portions at 3 and 12 hours

\begin{tabular}{|c|c|c|c|c|c|c|}
\hline \multirow{2}{*}{$\begin{array}{l}\text { Activating } \\
\text { substance }\end{array}$} & \multirow[t]{2}{*}{ Variable } & \multicolumn{5}{|c|}{ Blood component } \\
\hline & & Plasma & PC-A (3 h) & PC-A (12 h) & PC-B (3 h) & PC-B (12 h) \\
\hline \multirow[t]{5}{*}{ Calcium gluconate } & $\mathrm{TGF}-\beta_{1}(\mathrm{ng} / \mathrm{mL})$ & 7.99 (1.59) a & $23.97(2.03) b$ & $24.79(2.22) b$ & $26.03(2.23) b$ & $25.70(2.43) b$ \\
\hline & PDGF-BB (pg/mL) & $365.89(91.02) \mathrm{a}$ & $1571.56(204.5) b$ & $1420.32(139.4) b$ & $1552.23(188.1) b$ & $1400.75(131.5) b$ \\
\hline & Total protein $(\mathrm{mg} / \mathrm{mL})$ & $52.93(1.15) \mathrm{a}$ & $44.88(0.93) b$ & $46.70(1.36) b$ & $46.21(1.54) b$ & $46.67(1.71) b$ \\
\hline & TGF- $\beta_{1}(\mathrm{ng} / \mathrm{mg}$ of TP) & $0.15(0.03) \mathrm{a}$ & $0.53(0.04) b$ & $0.53(0.05) b$ & $0.57(0.05) b$ & $0.56(0.52) b$ \\
\hline & PDGF-BB (pg/mg of TP) & $6.91(1.82) \mathrm{a}$ & $35.02(4.12) b$ & $30.41(2.50) b$ & $33.59(3.66) b$ & $30.01(3.08) b$ \\
\hline \multirow[t]{5}{*}{ Bovine thrombin } & $\mathrm{TGF}-\beta_{1}(\mathrm{ng} / \mathrm{mL})$ & $7.99(1.59)$ a & $23.98(2.43) b$ & $28.22(2.59) \mathrm{b}$ & 30.56 (4.47) b & $35.74(4.18) b$ \\
\hline & PDGF-BB (pg/mL) & $365.89(91.02) \mathrm{a}$ & $1681.15(188.3) b$ & $1687.40(138.8) b$ & 1847.15 (208.3) b & $1683.16(122.7) b$ \\
\hline & Total protein $(\mathrm{mg} / \mathrm{mL})$ & $52.93(1.15) a$ & $42.29(1.37) b$ & $45.05(2.25) b$ & $43.20(2.35) b$ & $44.92(2.15) b$ \\
\hline & TGF- $\beta_{1}$ (ng/mg of TP) & $0.15(0.03) \mathrm{a}$ & $0.57(0.06) b$ & $0.65(0.07) b$ & $0.69(0.08) b$ & $0.79(0.09) b$ \\
\hline & PDGF-BB (pg/mg of TP) & $6.91(1.82) \mathrm{a}$ & $39.75(4.38) b$ & 37.45 (3.49) b & $42.77(5.29) b$ & $37.47(3.11) b$ \\
\hline
\end{tabular}

TGF- $\beta_{1=}$ transforming growth factor beta 1, PDGF-BB= platelet-derived growth factor type BB. Data presented as means (standard error). Different letters denote statistically significant differences between rows (Plasma vs. PCs) by SNK test $(P<0.05)$.

time ( 3 and $12 \mathrm{~h}$ ) (Table 2). When the TGF- $\beta_{1}$ concentrations were compared at 3 and 12 hours between each activating substance for each PC fraction, no statistically significant differences were found. No significant differences were observed when were compared the concentrations of TGF- $\beta 1$ ( $\mathrm{pg} / \mathrm{mg}$ of TP) in each PC (activated with either $\mathrm{BT}$ or $\mathrm{CG}$ ).

\section{Platelet-derived growth factor $\mathrm{BB}$ concentration}

The concentrations for the PDGF-BB were similar between each $\mathrm{PC}$ but were significantly higher $(\mathrm{P}<0.05)$ in comparison with the plasma. Both activating substances presented a similar effect on the release of this growth factor over time ( 3 and $12 \mathrm{~h}$ ). However, a significant difference was observed $(\mathrm{P}<0.05)$ in the concentrations of PDGF-BB ( $\mathrm{pg} / \mathrm{mg}$ of the TP) when the PC-B fraction was activated with $\mathrm{BT}$ at the 12 hours (Table 2).

\section{Correlations}

No statistically significant correlations were found between the evaluated parameters.

\section{Collection efficiency}

The platelet collection efficiencies were $26.16 \%$ and $24.75 \%$ for PC-A and PC-B, respectively, thereby giving a combined efficiency for the two portions of $50.91 \%$. The platelet concentrations were $183.10 \%$ and $173.28 \%$ higher with respect to whole blood for PC-A and PC-B, respectively. The growth factor collection efficiency at 3 and $12 \mathrm{~h}$ for each activating substance is presented in Table 3.

\section{Discussion}

This research describes a simple centrifugation manual (tube method) protocol to obtain PC from feline blood, thereby concentrating the growth factors such as TGF$\beta 1$ and PDGF-BB for experimental or clinical application in this species. The protocol described here presents the advantage that the PC is easily obtained with one centrifugation step with a small volume of blood. This last situation is important in feline practice because the volume of blood required to obtain PC for clinical application could be a limiting factor, especially in pediatric patients. To note, both PC obtained in this study could be classified as P-PRP.

We have not found any published studies about preparation of PC (either P-PRP or L-PRP) for clinical use in cats for regenerative medicine purposes. However, we did find information regarding manual methods for concentrating feline platelets for evaluating in vitro the effect of aggregating and anti-platelet substances in this species. In those studies, sodium citrate $3.8 \%$ was used as an anticoagulant. The studies included different centrifugation protocols

Table 3 Concentration efficiency of growth factors in the PC supernatants at 3 and 12 hours

\begin{tabular}{|c|c|c|c|c|c|c|c|}
\hline \multirow{2}{*}{$\begin{array}{l}\text { Activating } \\
\text { substance }\end{array}$} & \multirow[t]{2}{*}{ Variable } & \multicolumn{5}{|c|}{ Blood component } & \multirow[b]{2}{*}{$\mathrm{PC}-\mathrm{A}+\mathrm{B}(12 \mathrm{H})$} \\
\hline & & PC-A (3 h) & PC-A (12 h) & PC-B (3 h) & PC-B (12 h) & $P C-A+B(3 h)$ & \\
\hline \multirow[t]{2}{*}{ Calcium gluconate } & TGF- $\beta_{1}(\%)$ & 42.86 & 44.32 & 46.54 & 45.95 & 89.40 & 90.27 \\
\hline & PDGF-BB (\%) & 61.36 & 55.46 & 60.61 & 54.69 & 121.97 & 110.15 \\
\hline \multirow[t]{2}{*}{ Bovine thrombin } & TGF- $\beta_{1}(\%)$ & 42.88 & 50.46 & 54.64 & 63.90 & 97.52 & 114.36 \\
\hline & PDGF-BB (\%) & 65.64 & 65.88 & 72.12 & 65.82 & 137.76 & 131.70 \\
\hline
\end{tabular}

TGF- $\beta_{1=}$ transforming growth factor beta 1, PDGF-BB= platelet-derived growth factor type BB. 
ranging between $150-200 \mathrm{~g}$ and times of centrifugation ranging from 10-20 min [23-29]. These studies did not present data on the number of platelets concentrated or other hematological information with respect to the characteristics of those PC. For this reason, this study presents novel information about feline hematology with potential applications of $\mathrm{PC}$ for regenerative medicine purposes in cats.

The cellular characteristics obtained in both PC differed only in the highest concentration of LYM found in PC-A. This finding could suggest that each PC could display different biological effects mediated by this kind of cell when used clinically. This assumption can suggest a difference in clinical application characteristics of each portion due to the important regulatory effect of leukocytes in the healing process [30]. Particularly, lymphocytes are one major source of granulocyte-colony stimulating factor, granulocyte macrophage-colony stimulating factor, interleukin-1 and tumor necrosis factor alpha. These proteins have functions related to wound healing because they increase the activity of neutrophils and monocytes and promote the proliferation of keratinocytes and fibroblasts. All these actions are important in the inflammatory phase of wound healing [31]. However, this suggested mechanism is only an assumption, and additional experimental work is necessary to evaluate this hypothesis.

The platelet collection efficiency was low $(26.16 \%$ for PC-A and $24.75 \%$ for PC-B) in this study. This low efficiency is one of the main characteristics of manual methods (tube) to concentrate platelets in humans [32] and horses [33]. However, no other published results have been found for cats to compare with these results. The platelet collection efficiency obtained in this study could be sufficient (in terms of the concentration of platelets) to produce biological effects because the high concentrations of platelets could suppress cell viability and proliferation [34]. This concept is still controversial and should be the subject of future studies in cats. One limitation, with the platelet count of this study was that blood smears were not made to ensure no platelet clumping, this could be a potential limitation because clumping would influence the platelet counts.

The MPV represents the average size of the platelets, and PDW is an indicator of variation in the size of the platelets. The MPV and PDW values for automated hematology instruments would be increased during platelet activation [35]. The MPV and PDW values were lower in whole blood that in either PC. However, these platelet activation related parameters remained in a normal rank in both PC [36,37]. These values would indicate that the methodology used to obtain the PC in cats did not produce platelet activation. This concept is important if we consider that an effective method for concentrating platelets should first focus on obtaining functional and non-activated platelets instead of concentrating a large number of platelets [38]. In the light of procoagulant properties of feline platelets, this statement must be interpreted with caution and could be a limitation of this study.

Autologous platelet concentrate preparation involves a series of centrifugation and separation cycles for concentrating the platelets without inducing premature activation. The size and weight of the blood cells and the relative forces $(\mathrm{g})$ and time of centrifugation are the factors that determine the cellular and molecular characteristics of a PC. Studies in dogs [39], rabbits [40], pigs [41], horses [33] and humans [42] describe protocols with two rounds of centrifugation. One of these episodes is always greater than $240 \mathrm{~g}$, and one of the centrifugation times is greater than 10 minutes (except for horses). In the case of cats, the PLT can be concentrated by a soft spin (85 g) and short time (6 minutes). This methodological difference between species to obtain PC may be due to the morphological characteristics of cat platelets, such as higher diameter $(2-6 \mu \mathrm{m})$ [43] and mean platelet volume (8.6-14.1 fL) [36].

As described in a study in horses [33], samples were kept in incubation at room temperature $\left(20-22^{\circ} \mathrm{C}\right)$ for two hours after activation. In our case (incubation at $37^{\circ} \mathrm{C}$ ), within two hours after activation, we did not yet have complete formation of a fibrin clot in most of the PC samples. For this reason, the cat samples were left in incubation for another hour (three hour, total incubation time). This difference in time required for the formation of fibrin clots can be due additionally to the peculiar morphology of the platelets of both species and to the cellular count of the PC and whole blood of each species. The platelet counts in whole blood and PC in horses [33], are lower than those found in the cats in the present study; in particular, the PC show three-fold higher platelet concentrations in cats than in horses. This high concentration of platelets in cat PC compared with the results reported in horses [33] can lead to longer incubation times and/or higher doses of activating substance to obtain clots in cat PC.

It is reported a TGF- $\beta_{1}$ mean concentration of $21.48 \pm$ $8.948 \mathrm{ng} / \mathrm{mL}$ in serum samples taken from 12 cats [44]. This concentration was similar to the concentrations found in the supernatants of both PC but higher than the plasma TGF- $\beta_{1}$ concentration in this study. This discrepancy was caused by premature platelet activation. Serum differs from plasma in that the bulk of the fibrinogen has been removed by conversion into a fibrin clot together with the platelets that have either been physically bound in the fibrin matrix or activated to form aggregates or both [45]. This finding implies previous blood clotting and therefore platelet activation and 
release of the growth factors contained in the platelet alpha granules, including TGF- $\beta_{1}$.

We were not able to find any reports on feline PDGF$\mathrm{BB}$ plasma concentration. To the best of our knowledge, this study is the first time that an ELISA human kit for PDGF-BB was used to measure this protein in blood components from cats. However, it is reported that both human and cat PDGF-BB presented high peptide sequence homology [46]. A similar finding has also been noticed between human and equine PDGF-BB [47].

Once the PC is prepared, platelet activation (exogenous or endogenous) may be important to maximize growth factor release. Various substances have been described for the exogenous activation of $\mathrm{PC}$, including thrombin [48], batroxobin [49], collagen type I [50] and calcium chloride [2], among others. The substances most frequently used to activate PC for clinical purposes are thrombin and calcium salts. The use of topical bovine thrombin has been reported in humans to cause the formation of antibodies against the coagulation factor $\mathrm{V}$, prothrombin and thrombin [51]. Reports in mice show the formation of antibodies against autologous clotting factors and the induction of autoimmunity with features characteristic of systemic lupus erythematosus, including antibodies against nuclear antigens, native DNA, double-stranded DNA and cardiolipin [52]. For this reason, the clinical use of bovine thrombin as a platelet activator in feline medicine should be carefully studied. Reports in humans [53] and horses [54] investigated the use of autologous thrombin obtained by the addition of calcium gluconate to the plasma. PC activation with autologous thrombin might provide another option for clinical practice in cats, and the probability of immunological reactions would be reasonably smaller. In addition, the results of this study reported that CG has an action comparatively equipotent to BT. These reasons suggest the use of CG to induce gelation of the PC for clinical purposes in cats.

\section{Conclusion}

In conclusion, the methodology presented in this report permits the concentration of platelets potentially suitable for clinical and experimental use in feline medicine. The presence of significantly higher amounts of growth factors in the supernatant of PC compared to plasma indicates that PC can be used as a source of growth factors. The presence of high numbers of lymphocytes in PC-A may indicate different clinical applications for each PC. The temporary release of the growth factors indicates that the bulk of the growth factors are released during the first 3 hours after PC activation. The lack of differences in growth factor concentrations indicates that for this concern, PC activation can be made with either calcium gluconate or thrombin. The clinical value of the data reported here requires further evaluation in clinical settings.

\section{Methods}

The ethics committee of animal research of Federal University of Minas Gerais approved this study. Owners of the cats included were informed of the nature of the research and signed an authorized consent prior sedation and blood collection.

\section{Animals}

Sixteen mixed breed cats from local owners were used, specifically, eight males and eight females with an age range between 18 to 108 months and mean body weight of $3.4 \mathrm{~kg}$ that were clinically healthy at the time of blood collection. Cats with a basal platelet count less than 300 $\times 10^{3} \mathrm{PLT} / \mu \mathrm{L}$ were not included (normal basal minimum count) [55].

\section{Preparation of platelet concentrates}

After the cats were sedated (xylazine, $0.5 \mathrm{mg} / \mathrm{kg}+$ butorphanol $0.1 \mathrm{mg} / \mathrm{kg}$, IM), blood was collected by puncturing the jugular vein with a $21 \mathrm{G}$ butterfly catheter. The blood samples were collected into two $8.5 \mathrm{~mL}$ tubes containing $1.5 \mathrm{~mL}$ of ACD-A solution (trisodium citrate $22 \mathrm{~g} / \mathrm{L}$, citric acid $8 \mathrm{~g} / \mathrm{L}$ and dextrose $24.5 \mathrm{~g} / \mathrm{L}$ ) (Becton Dickinson and Company Vacutainer, New Jersey, USA). Seven $\mathrm{mL}$ of whole blood was collected per tube.

To obtain both PC, the blood was centrifuged (Hettich Rotofix 32A, Tuttlingen, Germany) at $85 \mathrm{~g}$ for $6 \mathrm{~min}$ utes. The plasma derived from the blood centrifugation was arbitrarily divided into two equal fractions, namely, PC-A and PC-B. Platelet concentrate-A (lower fraction) was considered as the first 50\% plasma fraction near to the packed cell volume (PCV), and PC-B (upper fraction) represented the $50 \%$ remaining plasma.

\section{Hemogram}

Samples from whole blood and both PCs were analyzed using an automated counting device by volumetric impedance (MEK-6400, Nihon Kohden, Tokyo, Japan). Each sample was analyzed in duplicate. The hematological parameters determined were PCV, platelet count (PLT/ $\mu \mathrm{L})$, red blood cell count (RBC) and white blood cell count $(\mathrm{WBC} / \mu \mathrm{L})$. The absolute $($ cell $/ \mu \mathrm{L})$ and relative (\%) counts for lymphocytes (LYM), monocytes (MON), granulocytes (GRA) and eosinophils (EOS) were determined. The platelet activation associated parameters, mean platelet volume (MPV fL) and platelet distribution width (PDW \%) were also analyzed.

\section{Activation of platelet concentrates}

One milliliter of PC-A and $1 \mathrm{~mL}$ of PC-B were divided into $500-\mu \mathrm{L}$ aliquots and activated with the addition of 
either $50 \mu \mathrm{L}$ of calcium gluconate 10\% (Ropsohn Therapeutics Ltda, Bogotá, Colombia) or $50 \mu \mathrm{L}$ of a bovine thrombin solution (BioPharm Laboratories LLC, Bluffdale, Utah, USA) containing $500 \mathrm{IU} / \mathrm{mL}$. After activation, the samples were kept at $37^{\circ} \mathrm{C}$ in an incubator. One hundred fifty $\mu \mathrm{L}$ of supernatant (after spontaneous clot retraction) of each PC were collected at 3 and 12 hours after PC activation. In addition, plasma samples were obtained by centrifugation of the whole blood at $1500 \mathrm{~g}$ for 15 minutes. The supernatants of the activated PC (platelet gel) and plasma samples were aliquoted and frozen at $-82^{\circ} \mathrm{C}$ for subsequent determination of the TGF- $\beta_{1}$ and PDGF-BB concentrations.

\section{Determination of total protein}

The total protein concentration (TP) was measured in both PC and plasma with the biuret method (Biosystems, Barcelona, Spain) in a semiautomatic chemistry analyzer (RT-1904CV, Shenzhen, China).

Determination of the concentration of transforming growth factor beta 1 and platelet-derived growth factor type BB

The concentrations of both GF in both PC and plasma were determined by an ELISA of development with antibodies to human TGF- $\beta_{1}$ (Human TGF-beta 1 DuoSet, DY240E, R\&D System, Minneapolis, MN, USA) and human PDGF-BB (Human PDGF-BB Duoset DY220E, R\&D Systems, Minneapolis, MN, USA). ELISA was performed according to the instructions of the manufacturer. The mean detection sensitivity was $4.6 \mathrm{pg} / \mathrm{mL}$ for TGF- $\beta_{1}$ and less than $15 \mathrm{pg} / \mathrm{mL}$ for PDGF-BB. Measurements of the concentrations of both GF were performed in duplicate at $450 \mathrm{~nm}$.

\section{Statistical analysis}

All the evaluated parameters presented normal distribution (Shapiro-Wilk test, $\mathrm{P}>0.05$ ) and were presented as means and mean standard error. Comparisons between the groups were performed using a one-way ANOVA, and post-hoc par-wise comparisons were performed using a Student-Newman-Keuls (SNK) test. A paired $t$ test was used to compare the temporal release of both GF at 3 and $12 \mathrm{~h}$. Correlations between the GF concentrations and the cellular data were determined using a Pearson test. A value of $\mathrm{P}<0.05$ was accepted as statistically significant for all of the tests.

\section{Collection efficiency}

The platelet collection efficiency was determined using the following formula: $(\mathrm{PC}$ volume $\times$ platelet count in the $\mathrm{PC} /$ whole blood volume $\times$ platelet count in whole blood $\times 100$ [56]. The GF concentration efficiency was determined using the formula (GF concentration $\times$ PC volume / plasma GF concentration $\mathrm{x}$ whole blood volume) $\times 100$ [32].

\section{Abbreviations}

CG: Calcium gluconate; BT: Bovine thrombin; EOS: Eosinophils; GF: Growth factors; GRA: Granulocytes; LYM: Lymphocytes; L-PRP: Leukocyte-platelet rich plasma; MON: Monocytes; MPV: Mean platelet volume; PC: Platelet concentrates; PCV: Packet cell volume; PDGF-BB: Platelet-derived growth factor type BB; PDW: Platelet distribution width; PLT: Platelets; P-PRP: Pureplatelet rich plasma; TGF- $\beta_{1}$ : Transforming growth factor beta 1 ; TP: Total protein.

\section{Competing interests}

Authors declare no competing interests related with this manuscript.

\section{Authors' contributions}

RFS conceived of the study, performed the laboratory tests, performed the statistical analysis and participated in the drafting of the manuscript. MEA, $\mathrm{DLR}$ and $\mathrm{CL}$, collected samples and performed the laboratory tests. CMFR participated in the design and participated in the drafting of the manuscript. JUC coordinated the study, participated in the design and harmonized the drafting of the manuscript. All authors read and approved the final manuscript.

\section{Acknowledgements}

We thank Vicerrectoría de Investigaciones y Postgrados from the Universidad de Caldas, Colombia, and Coordenação de Aperfeiçoamento de Pessoal de Nível Superior - CAPES and Fundação do Amparo à Pesquisa do Estado de Minas Gerais - FAPEMIG, Brazil.

Received: 12 June 2012 Accepted: 23 October 2012

Published: 6 November 2012

\section{References}

1. Carmona JU, Lopéz C, Sandoval J: Review of the currently available system to obtain platelet related products to treat equine musculoskeletal injuries. Rec Pat Regen Med 2012, 3:1. doi:10.2174/ 2210212700122882965

2. Carmona JU, Argüelles D, Climent F, Prades M: Autologous platelet concentrates as a treatment of horses with osteoarthritis: a preliminary pilot clinical study. J Equine Vet Sci 2007, 27(4):167-170.

3. Georg R, Maria C, Gisela A, Bianca C: Autologous conditioned plasma as therapy of tendon and ligament lesions in seven horses. J Vet Sci 2010, 11(2):173-175

4. Bosch G, René Van Weeren P, Barneveld A, van Schie HT: Computerised analysis of standardised ultrasonographic images to monitor the repair of surgically created core lesions in equine superficial digital flexor tendons following treatment with intratendinous platelet rich plasma or placebo. Vet J 2011, 187(1):92-98.

5. Monteiro SO, Lepage OM, Theoret CL: Effects of platelet-rich plasma on the repair of wounds on the distal aspect of the forelimb in horses. Am J Vet Res 2009, 70(2):277-282

6. You TM, Choi BH, Li J, Jung JH, Lee HJ, Lee SH, Jeong SM: The effect of platelet-rich plasma on bone healing around implants placed in bone defects treated with Bio-oss: a pilot study in the dog tibia. Oral Surg Oral Med Oral Pathol Oral Radiol Endod 2007, 103(4):8-12.

7. Dutra CEA, Pereira MM, Serakides R, Rezende MCF: In vivo evaluation of bioactive glass foams associated with platelet-rich plasma in bone defects. J Tissue Eng Regen Med 2008, 2(4):221-227.

8. Casati MZ, Vasconcelos-Gurgel BC, Gonçalves PF, Pimentel SP, Rochanogueira G, Nociti JRFH, Sallum EA: Platelet-rich plasma does not improve bone regeneration around peri-implant bone defects - a pilot study in dogs. Int J Oral Maxillofac Surg 2007, 36(2):132-136.

9. Appel TR, Pötzsch B, Müller J, von Lindern JJ, Bergé SJ, Reich RH: Comparison of three different preparations of platelet concentrates for growth factor enrichment. Clin Oral Implants Res 2002, 13(5):522-528.

10. Beldon P: Basic Science of wound healing. Surgery 2010, 28(9):409-412.

11. Roberts DE, Archibald MN, Ratna B: Mechanism of collagen activation in human platelets. J Biol Chem 2004, 279(9):19421-19430.

12. Bergmeier W, Stefanini L: Novel molecules in calcium signaling in platelets. J Thromb Haemost 2009, 7(S1):187-190.

13. Jennings LK: Mechanisms of platelet activation: need for new strategies to protect against platelet-mediated atherothrombosis. Thromb Haemost 2009, 102(2):248-257. 
14. Khan ML, Nakanishi-Matsui M, Shapiro MJ, Ishihara H, Coughlin SR: Protease-activated receptors 1 and 4 mediate activation of human platelets by thrombin. J Clin Invest 1999, 103(6):879-887.

15. Chandler JC, Beale BS: Feline Orthopedics. Clin Tech Small Anim Prac 2002, 17(4):190-203

16. Sánchez M, Azofra J, Anitua E, Andía I, Padilla S, Santisteban J, Mujika I: Plasma rich in growth factors to treat an articular cartilage avulsion: a case report. Med Sci Sports Exerc 2003, 35(10):1648-1652.

17. Alio JL, Abad M, Artola A, Rodriguez-Prats JL, Pastor S, Ruiz-Colecha J: Use of autologous platelet-rich plasma in the treatment of dormant corneal ulcers. Ophthalmology 2007, 114(7):1286-1293.

18. Thor A, Franke-Stenport V, Johansson CB, Rasmusson L: Early bone formation in humans bone grafts treated with platelet-rich plasma: preliminary histomorphometric results. Int J Oral Maxillofac Surg 2007, 36(12):1164-1171.

19. Greppi N, Mazzucco L, Galetti G, Bona F, Petrillo E, Smacchia C, Raspollini E, Cossovich P, Caprioli R, Borzini P, Rebulla P, Marconi M: Treatment of recalcitrant ulcers with allogeneic platelet gel from pooled platelets in aged hypomobile patients. Biologicals 2011, 39(2):73-80.

20. Argüelles D, Carmona JU, Climent F, Muñoz E, Prades M: Autologous platelet concentrates as a treatment for musculoskeletal lesions in five horses. Vet Rec 2008, 162(7):208-211.

21. Waselau M, Sutter WW, Genovese RL, Bertone AL: Intralesional injection of platelet-rich plasma followed by controlled exercise for treatment of midbody suspensory ligament desmitis in standardbred racehorses. J Am Vet Med Assoc 2008, 232(10):1515-1520.

22. Intini $\mathrm{G}$ : The use of platelet-rich plasma in bone reconstruction therapy. Biomaterials 2009, 30(28):4956-4966.

23. Grossklaus CHR, Damerau B, Lemgo E, Vogt W: Induction of platelet aggregation by the complement-derived peptides C3a and C5a. Naunym-Schmiedeberg's arch Pharmacol 1976, 295(1):71-76.

24. Burke SE, Dicola G, Lefer AM: Protection of ischemic cat myocardium by cgs-13080, a selective potent throboxane $A_{2}$ synthesis inhibitor. J Cardiovas Pharmacol 1983, 5(5):842-847.

25. Burke SE, Lefer AM, Nicolaou KC, Smith GM: SMITH JB: Responsiveness of platelets and coronary arteries from different species to synthetic thromboxane and prostaglandin endoperoxide analogues. $\mathrm{Br} J$ Pharmacol 1983, 78(2):287-292

26. Hayes KG, Pronczuk A, Addesa AE, Stephan ZF: Taurine modulates platelet aggregation in cats and humans. Am J Clin Nutr 1989, 49(6):1211-1216.

27. Johnson G, Tsao PS, Mulloy D, Lefer AM: Cardioprotective effects of acidified sodium nitrite in myocardial ischemia with reperfusion. J Pharmacol Exp Ther 1990, 252(1):35-41.

28. Murohara T, Scalia R, Lefer AM: Lysophosphatidylcholine promotes P-selectin expression in platelets and endothelial cells. Possible involvement of protein kinase C activation and its inhibition by nitric oxide donors. Circ Res 1996, 78(5):780-789.

29. Hayward R, Campbell B, Shin YK, Scalia R, Lefer AM: Recombinant soluble P-selectin glycoprotein ligand-1 protects against myocardial ischemic reperfusion injury in cats. Cardiovasc Res 1999, 41(1):65-76.

30. Park JE, Barbul A: Understanding the role of immune regulation in wound healing. Am J Surg 2004, 187(5A):11S-16S.

31. Enoch S, Leaper DJ: Basic science of wound healing. Surgery 2008 , 26(2):31-37.

32. Weibrich G, Kleis WK, Hitzler WE, Hafner G: Comparison of the platelet concentrate collection system with the plasma-rich-in growth factors kit to produce platelet rich plasma: a technical report. Inter J Oral Maxillofac Implants 2005, 20(1):118-123.

33. Argüelles D, Carmona JU, Pastor J, Iborra A, Viñals L, Martínes P, Bach E, Prades $M$ : Evaluation of single and double centrifugation tube methods for concentrating equine platelets. Res Vet Sci 2006, 81(2):237-245.

34. Choi BH, Zhu SJ, Kim BJ, Huh JY, Lee SH, Jung JH: Effect of platelet richplasma (PRP) concentration on the viability and proliferation of alveolar bone cells: an in vitro study. Int J Oral Maxillofac Surg 2005, 34(4):420-424.

35. Vagdatli E, Gounari E, Lazaridou E, Katsibourlia E, Tsikopoulou F, Labrianou I: Platelet distribution width: a simple, practical and specific marker of activation of coagulation. Hippokratia 2010, 14(1):28-32.

36. Boudreaux MK, Ebbe S: Comparison of platelet number, Mean platelet volume and platelet mass in five mammalian species. Comp Haematol Int 1998, 8(1):16-20.
37. Moritz A, Walcheck BK, Weiss DJ: Evaluation of flow cytometric and automated methods for detection of activated platelets in dogs with inflammatory disease. Am J Vet Res 2005, 66(2):325-329.

38. Marx RE: Platelet-rich plasma: evidence to support its usage. J Oral Maxillofac Surg 2004, 62(4):489-496.

39. Thoesen MS, Vanden Berg-Foels WS, Stokol T, Rassnick KM, Jacobson MS, Kevy SV, Todhunter RJ: Use of a centrifugation-based, point-of-care device for production of canine autologous bone marrow and platelet concentrates. Am J Vet Res 2006, 67(10)):1655-1661.

40. Kanthan SR, Kavitha G, Addi S, Choon DSK, Kamarul T: Platelet-rich plasma (PRP) enhaces bone healing in non-united critical-sized defects: a preliminary study involving rabbit models. Injury 2011, 42(8):782-789.

41. Fresno L, Fondevila D, Bambo O, Chacaltana A, García F, Andaluz A: Effects of platelet-rich plasma on intestinal wound healing in pigs. Vet J 2010, 185(3):322-327.

42. Anitua E, Andía I, Sanchez M, Azofra J, del Mar Zalduendo M, de la Fuente $M$, Nurden P, Nurden AT: Autologous preparations rich in growth factors promote proliferation and induce VEGF and HGF production by human tendon cells in culture. J Orthop Res 2005, 23(2):281-286.

43. Boudreaux MK, Osborne CD, Herre AC, Rivera ER, Spangler EA: Unique structure of the $\mathrm{M}$ loop region of $\beta 1$-tubulin may contribute to size variability of platelets in the family Felidae. Vet Clin Pathol 2010, 39(4):417-423

44. Arata S, Ohmi A, Mizukoshi F, Baba K, Ohno K, Setoguchi A, Tsujimoto H: Urinary transforming growth factor-beta 1 in feline chronic renal failure. J Vet Med Sci 2005, 67(12):1253-1255.

45. Sapan CV, Lundblad RL: Considerations regarding the use of blood samples in the proteomic identification of biomarkers for cancer diagnosis. Cancer Genomics Proteomics 2006, 3(3-4):227-230.

46. Van den Ouweland AM, Van Groningen JJ, Schalken JA, Van Neck HW, Bloemers HP, Van de Ven WJ: Genetic organization of the c-sis transcription unit. Nucleic Acids Res 1987, 15(3):959-970.

47. Donnelly BP, Nixon AJ, Haupt JL, Dahlgren LA: Nucleotide structure of equine platelet-derived growth factor- $A$ and $-B$ and expression in horses with induced acute tendinitis. Am J Vet Res 2006, 67(7):1218-1225.

48. Mazzucco L, Balbo V, Cattana E, Guascino R, Borzini P: Not every PRP-gel is born equal. Evaluation of growth factor availability for tissues through four PRP-gel preparations: fibrinet, regenPRP-Kit, plateltex and one manual procedure. Vox Sang 2009, 97(2):110-118.

49. Mazzucco L, Balbo V, Cattana E, Borzini P: Platelet-rich plasma and platelet gel preparation using Plateltex. Vox Sang 2008, 94(3):202-208.

50. Fufa D, Shealy B, Jacobson M, Kevy S, Murray MM: Activation of platelet-rich plasma using soluble type I colagen. J Oral Maxillofac Surg 2008, 66(4):684-690.

51. Ortel TL, Mercer MC, Thames EH, Moore KD, Lawson JH: Immunologic impact and clinical outcomes after surgical exposure to bovine thrombin. Ann Surg 2001, 233(1):88-96.

52. Schoenecker JG, Johnson RK, Lesher AP, Day JD, Love SD, Hoffman MR, Ortel TL, Parker W, Lawson JH: Exposure of mice to topical bovine thrombin induces systemic autoimmunity. Am J Pathol 2001, 159(5):1957-1969.

53. Crovetti G, Martinelli G, Issi M, Barone M, Guizzardi M, Campanati B, Moroni M, Carabelli A: Platelet gel for healing cutaneous chronic wounds. Transfus Apher Sci 2004, 30(2):145-151.

54. DeRossi R, Coelho AC, Mello GS, Frazilio FO, Leal CR, Facco GG, Brum KB: Effects of platelet rich-plasma gel on skin healing in surgical wound in horses. Acta Cir Bras 2009, 24(4):276-281.

55. O'Brien M, Murphy MG, Lowe JA: Hematology and clinical chemistry parameters in the cat (Felis domesticus). J Nutr 1998, 128(12):2678S-2679S.

56. Weibrich G, Wilfried KGK, Rainer B, Hitzler WE, Hafner G: The Harvest Smart PRePTM system versus the Friadent-Schütze platelet-rich plasma kit. Clin Oral Implants Res 2003, 14(2):233-239.

\section{doi:10.1186/1746-6148-8-212}

Cite this article as: Silva et al:: Evaluation of the effect of calcium gluconate and bovine thrombin on the temporal release of transforming growth factor beta 1 and platelet-derived growth factor isoform BB from feline platelet concentrates. BMC Veterinary Research $20128: 212$ 